\title{
The carbon emissions of Chinese cities
}

\author{
H. Wang ${ }^{1,2}$, R. Zhang ${ }^{1}$, M. Liu ${ }^{1}$, and J. Bi ${ }^{1,2}$ \\ ${ }^{1}$ State Key Laboratory of Pollution Control and Resource Reuse, School of the Environment, Nanjing University, \\ Nanjing 210046, China \\ ${ }^{2}$ Institute for Climate and Global Change Research, Nanjing University, Nanjing 210046, China
}

Correspondence to: J. Bi (jbi@nju.edu.cn)

Received: 2 February 2012 - Published in Atmos. Chem. Phys. Discuss.: 21 March 2012

Revised: 26 June 2012 - Accepted: 27 June 2012 - Published: 18 July 2012

\begin{abstract}
As increasing urbanization has become a national policy priority for economic growth in China, cities have become important players in efforts to reduce carbon emissions. However, their efforts have been hampered by the lack of specific and comparable carbon emission inventories. Comprehensive carbon emission inventories for twelve Chinese cities, which present both a relatively current snapshot and also show how emissions have changed over the past several years, were developed using a bottom-up approach. Carbon emissions in most Chinese cities rose along with economic growth from 2004 to 2008. Yet per capita carbon emissions varied between the highest and lowest emitting cities by a factor of nearly 7 . Average contributions of sectors to per capita emissions for all Chinese cities were $65.1 \%$ for industrial energy consumption, $10.1 \%$ for industrial processes, $10.4 \%$ for transportation, $7.7 \%$ for household energy consumption, $4.2 \%$ for commercial energy consumption and $2.5 \%$ for waste processing. However, these shares are characterized by considerable variability due to city-specific factors. The levels of per capita carbon emissions in China's cities were higher than we anticipated before comparing them with the average of ten cities in other parts of the world. This is mainly due to the major contribution of the industry sector in Chinese cities.
\end{abstract}

\section{Introduction}

As global climate changes become more apparent, efforts to control and reduce greenhouse gas (GHG) emissions have become a focus of worldwide attention. But the outcome of COP 15 in Copenhagen in December 2009 has made it clear that differences in the circumstances and interests of individ- ual countries will make it difficult to agree on common GHG reduction targets and strategies at the international level.

Nonetheless, bottom-up approaches to this problem are emerging in many countries (Gurney et al., 2009), and cities are taking on important roles in global efforts to address climate change (Hillman and Ramaswami, 2010; Koehn, 2008). Since cities contribute over $67 \%$ of the global GHG emissions from fossil fuel use (Satterthwaite, 2008), developing benchmarks and more comprehensive carbon emission inventories at the city level has become necessary in the context of global efforts to mitigate climate change (Gertz, 2009; Ramaswami et al., 2008). Creating carbon emissions inventories and improving the understanding of how and why cities differ in terms of emissions are essential to success in this realm (Kennedy et al., 2009). To make progress, however, a common and comparable carbon accounting system is needed.

Previous efforts have employed accounting systems like the one developed by the International Council for Local Environmental Initiatives (ICLEI, 2008). But most of these studies have calculated GHG emissions for a specific city or a particular year, and they have not compared the components of GHG inventories using a consistent methodology. Lifecycle and demand-centered methodologies are thought to be able to assign emissions to political jurisdictions more accurately (Ramaswami et al., 2008; Larsen and Hertwich, 2009; Schulz, 2010). However, the lack of data on comprehensive consumptions at the city-scale and especially for cities in developing countries (Hillman and Ramaswami, 2010) constitutes a severe problem for studies of this kind. Moreover, different understandings of the definition and boundary of the life-cycle (Matthews et al., 2008) make GHG emission data for cities difficult to compare and lead to risks of doublecounting in a spatial and temporal sense. To solve these 
problems, we propose a comprehensive carbon accounting approach, which is comparable to ICLEI's and with data availability for Chinese cities (Bi et al., 2011).

China has adopted the target of reducing $\mathrm{CO}_{2}$ emissions per unit of GDP by 40-45\% relative to 2005 levels by 2020 . But urbanization is considered a national policy priority in efforts to spur economic and industrial growth in China, and the government aims to increase the urbanization rate from $40 \%$ in 2005 to $60 \%$ by 2030 (UN, 2007). As rising incomes make urban dwellers' lifestyles more energy intensive and as migrants to the cities demand greater per capita energy than their rural counterparts (Dhakal, 2009), controlling energy consumption and GHG emissions becomes more difficult. Although there are several studies of GHG emissions for cities in China, they are usually based on calculations of aggregate city energy consumption using top-down approaches (Dhakal, 2009; Li et al., 2010; Lin et al., 2010). They give us proxies of the total GHG emissions. But they are usually not able to present enough information for the local governments to define operable measures to reduce carbon emissions compared with bottom-up approaches. Furthermore, these factors also make it difficult for the researchers to analyze the differences of carbon emissions between Chinese cities and other cities in the world. Bottom-up carbon emissions inventories for Chinese cities based on comparable accounting approaches are urgently needed.

This paper aims to analyze the GHG emission characteristics of China's mega-cities. We develop comprehensive and comparable carbon emissions inventories for twelve Chinese cities based on bottom-up approaches. Then, we analyze and compare the characteristics of GHG emissions in those cities. We also examine similarities and differences in GHG emissions between the cities in China and cities located in other countries. This is the first systematic accounting of Chinese GHG emissions at the city-scale based on a bottomup methodology where the emissions are compared with ten cities in the world. The results provide a benchmark in discussions of the effectiveness of strategies designed to reduce carbon emissions.

\section{Methodology}

\subsection{Chinese cities}

In order to represent various sizes and development characteristics, we analyze twelve Chinese cities: Beijing, Shanghai, Tianjin, Chongqing, Guangzhou, Hangzhou, Nanjing, Zhengzhou, Shenyang, Wuhan, Wuxi and Lanzhou. These cities are situated in different geographical regions of China as indicated in Fig. 1. Basic information about these cities and ten world cities used in the comparison is included in Table S1 (Supplement).
In China, major environmental policies are usually made at the national government level and implemented by local governments, such as provinces and cities. These cities are not the same as urban areas. They are administrative units, which usually include urban, town and rural populations.

\subsection{Components of a carbon emissions inventory}

In this study, we calculate carbon emissions, expressed in carbon dioxide equivalents $\left(\mathrm{CO}_{2 \mathrm{e}}\right)$, for six sectors of a city's GHG inventories, including industrial energy consumption, transportation, household energy consumption, commercial energy consumption, industrial processes and waste. The first 4 include emissions related to energy consumption, while the last two involve process and waste related emissions. Due to the high uncertainties and typically small contributions of agriculture, forest and other land use (AFOLU) to the total carbon emissions of cities (Kennedy et al., 2010), these emissions have not been included in this study. Because carbon emissions from biomass burning is largely offset by annual vegetation re-growth (Houghton and Hackler, 1999), the contribution of biomass use is often omitted in long-term analyses of atmospheric $\mathrm{CO}_{2}$ data (Yantosca et al., 2004; IPCC, 2006). We have adopted this procedure in our study. The specific methods used in calculating carbon emissions for each sector are discussed in our previous paper (Bi et al., 2011), and only the most salient details are provided here. The carbon accounting scope of this study is illustrated in Table S2.

\subsubsection{Energy consumption}

This sector includes primary and secondary energy consumption relating to industrial, transportation, residential and commercial activities. In this study, GHG emissions from energy consumption are calculated by multiplying energy consumption of subsectors (e.g. coal and oil for energy types) and corresponding emission factors, which are summarized in Eq. (1).

$\mathrm{GHG}=\sum_{i, j}\left[C_{i, j} \cdot \mathrm{EF}_{j}\right]$

where, $i$ represents subsectors in a typical sector (e.g. the transportation sector can be divided into passenger cars, heavy duty trucks, buses, etc.); $j$ represents energy types (e.g. coal, oil, electricity, etc.); $\mathrm{GHG}$ is the sector's total $\mathrm{CO}_{2 \mathrm{e}}$ emissions, ton; $C_{i, j}$ is energy consumption per sub-sector (the units correspond to various energy type, such as tons for coal, $\mathrm{m}^{3}$ for the natural gas, $\mathrm{kWh}$ for the electricity, etc.); $\mathrm{EF}_{j}$ represents the $\mathrm{CO}_{2 \mathrm{e}}$ emission factors for specific energy types.

\subsubsection{Industrial processes}

Carbon emissions from industrial processes mainly refer to those emitted from the chemical or physical transformation of materials during industrial production, such as cement 

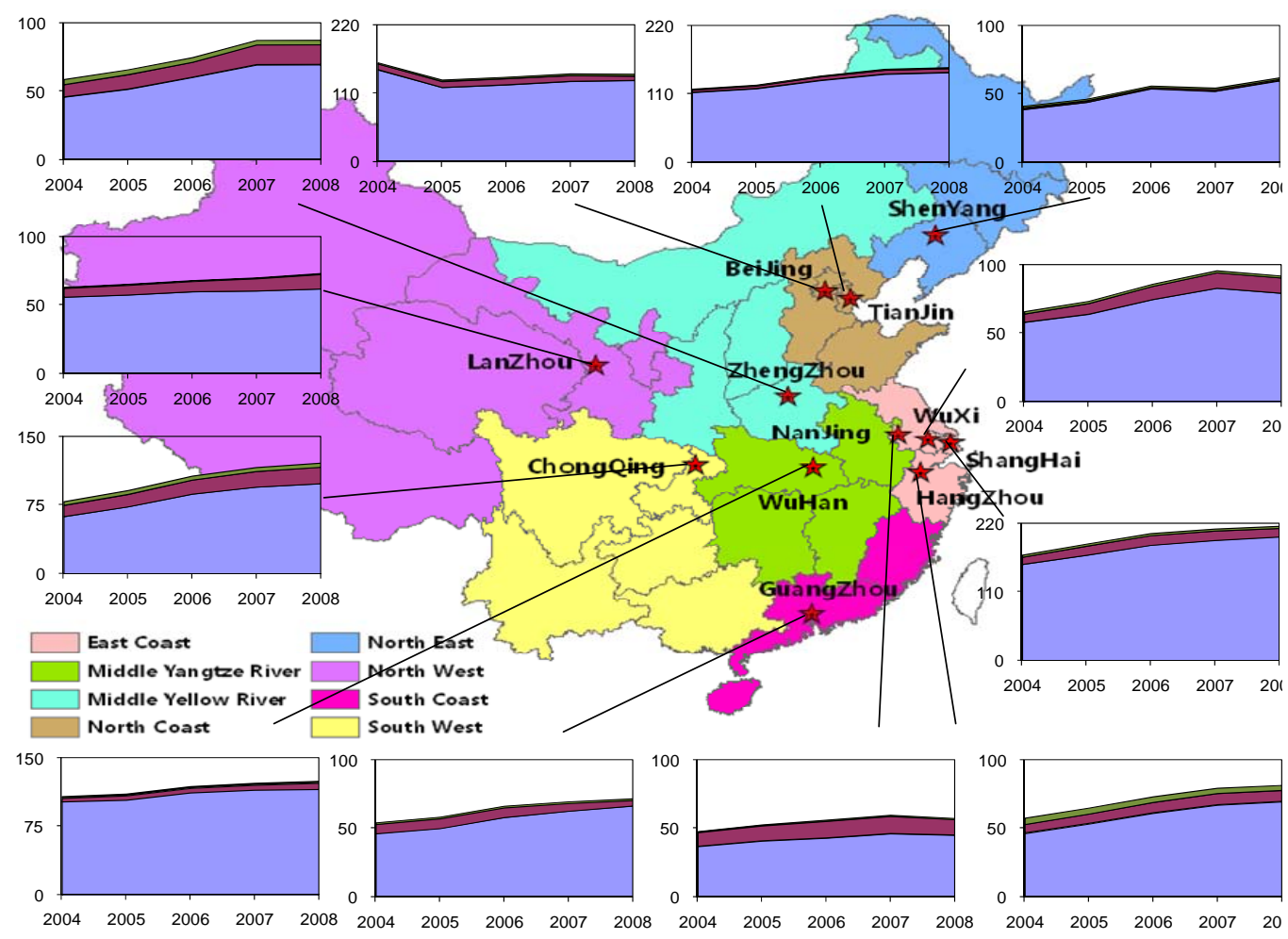

Energy consumption

Industry process

Waste treatment

Fig. 1. Carbon emissions of the 12 cities in China from 2004 to 2008.

manufacturing and limestone consumption. Emissions associated with combustion to produce energy for industrial use are excluded from this sector. The $\mathrm{CO}_{2 \mathrm{e}}$ emissions from this sector are calculated according to the outputs of various products. Because of constraints relating to the availability of information regarding industrial processes at the city level, we focused on the carbon emissions from three major sources (cement and glass, chemical, and metal productions).

\subsubsection{Waste}

We applied IPCC's (2006) First Order Decay approach to account for carbon emissions from landfill waste. This approach ideally requires at least $20 \mathrm{yr}$ of landfill data and good estimates of decay coefficients. The data on industrial solid waste were obtained from the city statistical yearbooks. Municipal solid waste production was estimated based on the population of cities. Because there are few studies with methane emissions from landfills in Chinese cities, we applied the IPCC's recommended parameters for developing countries.

\subsection{Overall carbon emissions}

In this study, the ICLEI (2008) metrics were applied as much as possible to maximize the comparability of our results with those from other cities in the world. Comparisons of the carbon accounting scopes between ICLEI and this study are shown in Table S2. A city's overall carbon emissions include emissions from fossil fuel combustion and industrial processes occurring within the city boundaries, electricity use, and waste disposal. Although some cities export their solid waste beyond their boundaries, methane emissions from landfills are still included here.

In order to allow comparisons across cities and to assess the consistency of GHG emissions across various scales, we normalized the total GHG emissions for the 12 Chinese cities on a per capita or per gross domestic product (GDP) basis and compared them with the emissions of other cities in the world. If not noted specifically, GDP has already been adjusted for purchasing power parity (PPP). We also divided per capita carbon emissions into non-industry and industry related emissions to reflect the impacts of personal consumption and industrial production on the carbon emissions of Chinese cities. 


\subsection{Data sources}

We collected data on industrial energy consumption, industrial production, vehicle population, GDP and population from the statistical yearbook of each city. Detailed references are provided in our supporting information. We calculated carbon emission factors for each fossil fuel used in Eq. (1) using the IPCC (2006) recommended methods. Vehicle miles traveled (VMT) and fuel economies were acquired from our previous studies (Wang et al., 2010a, 2011) and The First Census of Pollution Source in China.

We calculated carbon emissions from electricity on consumption basis to avoid double counting. This means that we excluded emissions from power plants in computing the total carbon emissions for a city. Therefore, carbon emissions from electricity depend on the amount consumed (not production) and the carbon emission intensity of the supply mix: (1) the electricity consumption is for all types of sectors (e.g. industrial, transportation, residential and commercial), which could be acquired from each city's statistics. (2) It is important to determine carbon emission factors of the electricity supply mix. There are six large power grids in China, named for the regions they serve: Northeast China, North China, Central China, East China, Northwest China, and South China. These grids are not strictly independent, as one grid may buy power from another if needed. In this study, we applied the electricity generation fuel mixes for these six power grids from 2004 to 2008 (SSBC, 2009) to calculate the carbon emission factors in different years. Power exchanges between the grids have also been considered. Coal and hydro are the two major energy sources for power generation in China, and the split between them varies by region. Coalbased power dominates in Northeast and North China generation mixes, with the proportion reaching as high as 95$98 \%$. Although coal remains dominant, the Northwest, Central, and South mixes include $22 \%$ or more of hydro power. The South and East China grids also include 5\% nuclear power (Huo et al., 2010). The carbon emission factors from 2004 to 2008 for the cities included in this study are presented in Table S3.

\section{Results and discussion}

\subsection{Profiles of carbon emissions of Chinese cities}

\subsubsection{Trends of carbon emissions}

China consists of eight economic regions (Chen et al., 2009), including the North East (Heilongjiang, Liaoning and Jilin), the North Coast (Beijing, Tianjin, Hebei and Shandong), the East Coast (Shanghai, Jiangsu and Zhejiang), the South Coast (Guangdong, Hainan and Fujian), the Middle Yangtze River (Anhui, Hubei, Hunan and Jiangxi), the Middle Yellow River (Henan, Shanxi, Inner Mongolia, Shaanxi), the South West (Sichuan, Guizhou, Yunnan, Chongqing and Guangxi) and the North West (Gansu, Ningxia, Qinghai, Tibet and Xinjiang). The 12 cities included in this study are distributed in these 8 economic regions as shown in Fig. 1.

Total carbon emissions for all the Chinese cities other than Beijing show growing emissions during the five years from 2004 to 2008. However, the growth rate in 2008 is not as high as experienced previously, and carbon emissions have even decreased for individual cities. Except for the improvement of energy use efficiencies, this is related to the global recession of 2008-2009. As shown in Fig. S1, the growth rates of exports and their contributions to the total GDP decreased in 2008 for most cities, especially those cities that have large export activities such as Shanghai, Guangzhou and Wuxi.

As China's capital city, Beijing's carbon emissions decreased in recent years mainly due to measures associated with the 2008 Olympic Games. To ensure good air quality for the games, Beijing's municipal government adopted an "Air Quality Guarantee Plan for the 29th Olympic Games" (Wang et al., 2010b). Starting in 2000, many energy intensive or heavy polluting industrial facilities (e.g. oil refineries and steel plants) were relocated; numerous coal-fired boilers and domestic stoves were modified to use natural gas, and older vehicles were replaced with newer, cleaner vehicles. Beijing also implemented other temporary measures during the period of the games, such as odd-even number permit policies for private cars on Beijing's roads (i.e. vehicles with a license plate ending in an odd number were allowed only on odd-number days while even numbers were allowed only on even-number days) (Zhou et al., 2010b) as well as production controls for some energy-intensive industries. Capital Iron and Steel General Corporation and Beijing Yanshan PetroChemical Corporation, for example, were required to reduce their operations by $30-50 \%$. Overall, Beijing's carbon emissions in 2008 were $19.32 \%$ below emissions in 2004 with an annual decrease rate of $5.22 \%$.

\subsubsection{Preliminary analysis of factors influencing carbon emissions}

The total carbon emissions of Chinese cities were found to correspond closely to GDP. The linear regression between these two variables is statistically significant $\left(t_{\text {stat }}=7.11\right.$, sig. $<0.001$ ) and has an $R^{2}$ of 0.47 (Table 1). Further regressions were conducted to analyze whether the population impacted city's carbon emissions. As shown in Table 1, the inclusion of population in a regression produced a better linear fit $\left(R^{2}=0.53\right)$. In the improved model, city population was statistically significant $\left(t_{\text {stat }}=2.74\right.$, sig. $\left.=0.008\right)$ but still secondary to GDP $\left(t_{\text {stat }}=5.54\right.$, sig. $\left.<0.001\right)$. Per unit area carbon emissions also correlated strongly with population density in China's cities $\left(t_{\text {stat }}=15.38\right.$, sig. $<0.001$; $R^{2}=0.80$ ). As the per capita carbon emissions of most Chinese cities have grown during the past five years (Fig. 3b), China's carbon emissions will inevitably increase in the near 
Table 1. Linear Regression Analysis for the Carbon Emissions of 12 Chinese cities.

\begin{tabular}{|c|c|c|c|c|}
\hline Variable & coefficient & $t_{\text {stat }}$ & sig. & $95 \% \mathrm{CI}$ \\
\hline \multicolumn{5}{|c|}{ Total carbon emission (thousand tons) $\left(R^{2}=0.47\right)$} \\
\hline Constant & 49162 & 8.09 & 0.000 & 36991 to 61334 \\
\hline GDP (million \$US in PPP) & 0.67 & 7.11 & 0.000 & 0.48 to 0.86 \\
\hline \multicolumn{5}{|c|}{ Total carbon emission (thousand ton) $\left(R^{2}=0.53\right)$} \\
\hline Constant & 41984 & 6.63 & 0.000 & 29305 to 54663 \\
\hline GDP (million \$US in PPP) & 0.55 & 5.61 & 0.000 & 0.36 to 0.75 \\
\hline city population (thousand people) & 1.25 & 2.74 & 0.008 & 0.34 to 2.17 \\
\hline \multicolumn{5}{|c|}{ Carbon emission density (ton $\left.\mathrm{km}^{-2}\right)\left(R^{2}=0.80\right)$} \\
\hline Constant & 602 & 0.91 & 0.369 & -728 to 1932 \\
\hline city population density (people $\mathrm{km}^{-2}$ ) & 8.97 & 15.38 & 0.000 & 7.80 to 10.14 \\
\hline \multicolumn{5}{|c|}{ Log per GDP carbon emission $\left(R^{2}=0.70\right)$} \\
\hline Constant & 15.29 & 22.72 & 0.000 & 13.94 to 16.63 \\
\hline Log GDP (million \$US in PPP) & -0.73 & -11.59 & 0.000 & -0.85 to -0.60 \\
\hline
\end{tabular}

future with more and more people crowding into big cities and rapid development of economy.

The carbon emission intensities (per GDP carbon emissions) of Chinese cities were found to decrease as a function of economic development (Table 1). The linear regression of $\log$ (per GDP carbon emission) and $\log$ (GDP) is statistically significant $\left(t_{\text {stat }}=-11.59\right.$, sig. $\left.<0.001\right)$ with good fit $\left(R^{2}=0.70\right)$. Combined with Fig. 3a, this indicates that there have already been some efforts by Chinese cities to reduce their carbon emission intensities to achieve the central government's objective, declared at COP 15 in Copenhagen, of reducing carbon emissions per unit of GDP by $40-45 \%$. As we indicated above, however, these efforts were counteracted by rapid economic development and urban population growth. As a result, total emissions have continued to increase during the past five years. To achieve absolute carbon emission reductions, China will have to adopt stronger measures to save energy and reduce emissions.

There is little correlation between per capita carbon emissions and per capita GDP $\left(t_{\text {stat }}=0.13\right.$, sig. $=0.89 ; R^{2}=$ 0.001 ), a finding that seems to conflict with the idea of the environmental Kuznets curve. Although China is experiencing rapid economic growth, development is extremely unbalanced with energy structures and technology levels differing greatly across regions. This may explain why per capita carbon emissions (or energy consumption) do not correspond with per capita GDP in China's cities.

\subsection{Carbon emission inventories and intercity comparisons among Chinese cities}

\subsubsection{Carbon emissions inventories}

Figure 2a shows carbon emissions from the six sectors for each of the twelve cities normalized on a per capita basis in 2008. Overall, carbon emissions covered a broad range from 3.72 to 22.54 tons $\mathrm{CO}_{2 \mathrm{e}}$ per person. Average contributions from individual sectors to total per capita carbon emissions and the ranges observed for each sector are displayed in Fig. 2b. Carbon emissions from industrial energy consumption represent the largest source, contributing $64.34 \%$ to total per capita $\mathrm{CO}_{2 \mathrm{e}}$ emissions. These emissions also exhibit the greatest variation across cities. Emissions from buildings, which include household and commercial sectors, are the second largest source with a contribution of $12.33 \%$ of total carbon emissions. The third largest contributor is transportation at $10.58 \%$, followed by the industry process sector at $10.23 \%$. The waste sector contributes only $2.51 \%$ of the total per capita carbon emissions on average.

\subsubsection{Intercity comparisons}

Although total carbon emissions of most Chinese cities have increased during the past five years (Fig. 1), the carbon emission intensities have decreased in all 12 cities (Fig. 3a). Average reduction is $25.86 \%$, which covers a range from $3.13 \%$ (Chongqing) to $63.64 \%$ (Beijing). It means that GDP increase faster than the carbon emissions of these cities. Because the energy and economic structures for most of the cities did not change in an obvious manner (see Figs. S2 and S3), this indicates the energy utilization efficiencies of Chinese cities have improved during the past five years. 


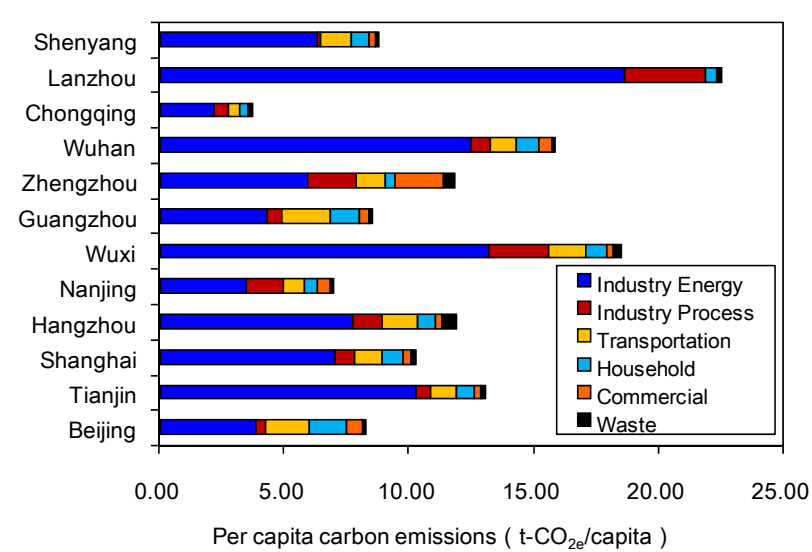

(a)

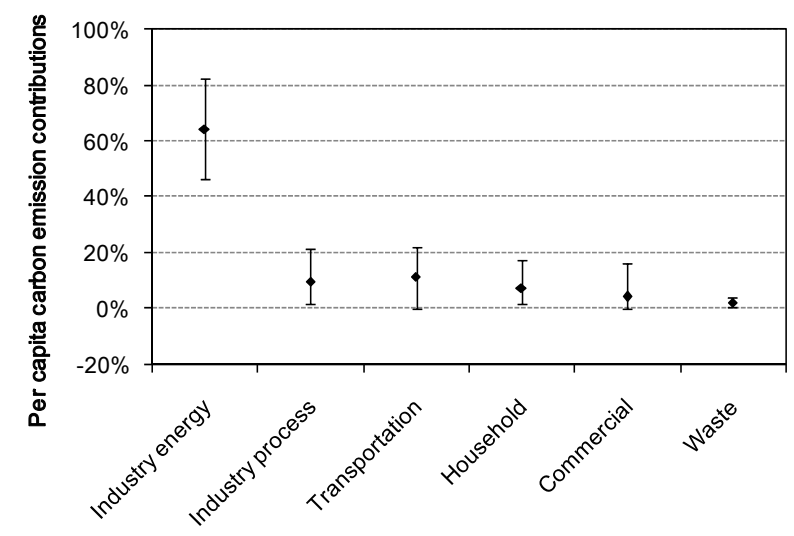

(b)

Fig. 2. Per capita carbon emissions (ton $\mathrm{CO}_{2 \mathrm{e}}$ ) by sector for all 12 China's cities in 2008: (a) individual city data of per capita carbon emissions; (b) sector contribution shares (mean and range values) across the 12 cities.

Structure changes within the industrial sector could also influence cities' energy uses. But this kind of impact could be positive or negative in individual cities. For example, the industrial carbon emissions of Beijing decreased through the transfer of energy intensive industries (e.g. oil refiners and big steel plants) to other cities (Fig. S4) and the development of tertiary industries (Fig. S3). On the other hand, the industrial carbon emissions of Tianjin increased as the city received some oil refiners and big steel plants from Beijing, even though the energy utilization efficiencies of these plants improved greatly.

The Yangtze River Delta (YRD), the Pearl River Delta and Beijing-Tianjin-Hebei (BTH) are the three most developed regions in China. They have the most active economies and most advanced technologies. As the core cities in these regions, Guangzhou (PRD), Beijing (BTH) and Shanghai

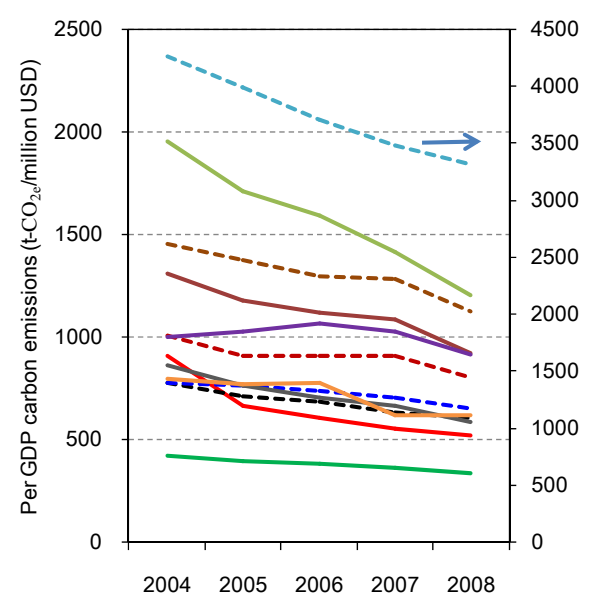

(a)

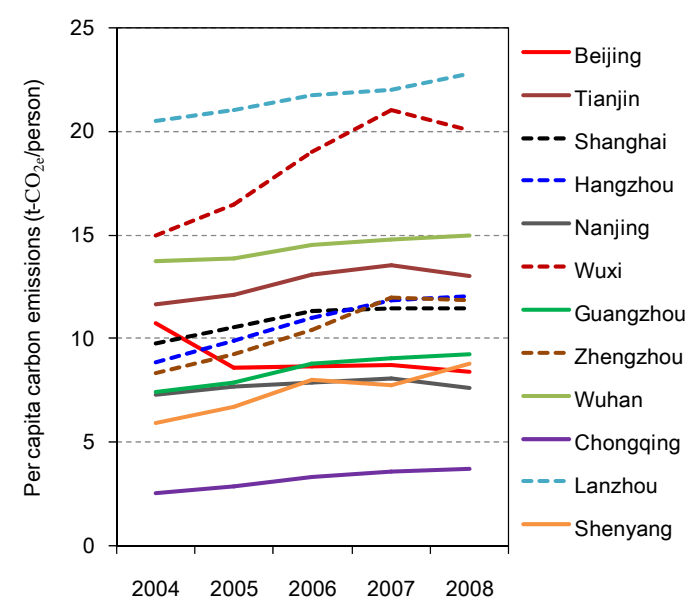

(b)

Fig. 3. Carbon emission characteristics of the 12 Chinese cities from 2004 to 2008: (a) per unit of GDP carbon emissions; (b) per capita carbon emissions.

(YRD) have the lowest per unit of GDP carbon emissions (Fig. 3a). By contrast, Lanzhou, a city in west China, has an economy mainly dependent on heavy industry, and its energy efficiency technologies lagged behind those of the most developed regions. Thus, Lanzhou's per GDP emissions were 4 to 10 times of the cities' in the three most developed regions.

As shown in Fig. 3b, per capita carbon emissions for all the cities other than Beijing show growth trends from 2004 to 2008 , although there are fluctuations among cities. This will put huge pressure on the local governments as they seek to realize their carbon mitigation ambitions. Per capita carbon emissions of most cities are within the range of 5 to 15 tons. Lanzhou's total carbon emissions are comparable to Guangzhou. However, its population is around 3 million and less than half of Guangzhou's. Therefore, the per capita carbon emissions differed by more than a factor of two between 
these cities. As the biggest municipality in China, Chongqing has the largest population of around 28 million, more than Shanghai (18 million) and Guangzhou (8 million) combined. At the same time, Chongqing is a less developed city and depends more on primary industry comparing to the other cities in China (see Fig. S3). These explain why the per capita carbon emission of Chongqing is the lowest among the 12 Chinese cities.

\subsection{Comparisons with other cities in the world}

To provide context, we compared carbon emission levels in Chinese cities with data on ten cities elsewhere in the world used in Kennedy's analysis (2009), which employs a similar accounting procedure to that used here. As Table 2 illustrates, eight of the twelve Chinese cities have per capita carbon emissions over $8.0 \mathrm{t}-\mathrm{CO}_{2 \mathrm{e}}$, making them comparable or even higher than the ten world cities. Carbon emissions in seven of the Chinese cities exceed the average value for the ten world cities. Several factors account for this phenomenon:

1. The definition of a city in China differs from the definition used in the United States. The Chinese definition is broader, encompassing more than the areas encompassed in the ten world cities (Table S1). As a result, many rapidly developing and highly energy intensive industries are included within cities in China. As industrial sectors, including industry energy consumption and industry processes, account for over $75 \%$ of the total carbon emissions in China's cities, it is easy to understand the higher per capita carbon emissions in Chinese cities compared to the world cities. On the other hand, according to IEA (2007), average per capita carbon emissions from energy use in China and the United States are respectively 6 and $25 \mathrm{t}-\mathrm{CO}_{2 \mathrm{e}}$. This means that per capita carbon emissions of cities are higher than the national average in China, while the reverse is true for cities in the United States included in the comparison.

2. Calculations for seven of the ten world cities did not include emissions from industry processes in the computation of total carbon emissions. However, industry process is the third largest sector in China, contributing $2-24 \%$ of total carbon emissions in individual cities. Seven of the 12 Chinese cities would have lower per capita carbon emissions than the average level for the ten non-Chinese cities if the contribution of industry processes were omitted.

3. The results of this study demonstrate that carbon emissions in China's cities are higher than we anticipated. But it is important to note that the 12 cities included in our assessment are among the most developed cities in each province of China. As we have noted, a city's carbon emissions are highly correlated with GDP. Inclusion of a wider selection of cities in China would reduce the level of average emissions. The analysis also revealed that the average per capita carbon emissions of China is small, but in the case of developed cities, such as some cities in this study, carbon emissions could be well above other cities in the developed world.

Because China is a major exporter, per capita carbon emissions may not be the best way to compare cities, for industrial emissions are the major contributor and vary widely among individual cities. In order to explore this issue, we divided per capita carbon emissions into per capita industrial and per capita non-industrial emissions. As can be derived from Table 2, the average per capita industrial emission is $8.25 \mathrm{t}-\mathrm{CO}_{2 \mathrm{e}}$ for Chinese cities, which is three times that of the ten world cities. However, the average for per capita non-industrial emissions is only $37 \%$ of the ten cities' in the world. This illustrates that the carbon emissions of Chinese cities are mainly caused by industrial production and that the carbon emissions from a citizen's everyday life are far below the average in ten world cities.

China's vehicle population (not including motorcycles) has increased nearly 3 times during the past decade. However, vehicle ownership is only 50 per 1000 persons, which is only $40 \%$ of the world average and just $5 \%$ of the average in the United States. For this reason, most cities in China (except the highly developed ones like Beijing and Guangzhou) have a much lower per capita carbon emissions resulting from ground transport compared with the ten world cities. This explains why ground transportation generates only $10 \%$ of total carbon emissions in China's cities, well below the $17-40 \%$ of emissions in the ten world cities. This is also supported by the fact that vehicles only consumed 6-7\% of the total energy in China, while in the developed countries vehicles consumed 20-30\% of total energy (He et al., 2005).

\subsection{Uncertainties}

A carbon emissions inventory for a city has inherent uncertainties because it simplifies complex real-world processes. The uncertainties may arise from many sources, some of which are common to all carbon emissions inventories, such as errors in emission factors caused by real-world emission variability. In this study, the main uncertainties in the carbon emission inventory for Chinese cities may come from the following areas:

1. The uncertainty associated with estimates of carbon emission factors for various types of energies/products. For example, the IPCC default emission factors were applied to the industrial processes and solid waste sectors.

2. The reality that some activity data, such as municipal solid waste generation, are rarely collected and reported in China's local statistics, and are difficult to obtain directly. We used waste generation rates at the national 
Table 2. Summary of the Per Capita Carbon Emissions from 12 Chinese Cities in 2005 and other Ten Cities in the World (t-CO $2 \mathrm{e} / \mathrm{capita}^{\mathrm{a}}$.

\begin{tabular}{|c|c|c|c|c|c|c|c|c|}
\hline \multirow[t]{2}{*}{ City } & \multirow[t]{2}{*}{$\begin{array}{l}\text { Electricity } \\
\text { Use }\end{array}$} & \multirow[t]{2}{*}{$\begin{array}{l}\text { Heating and } \\
\text { industrial fuel use }\end{array}$} & \multirow[t]{2}{*}{$\begin{array}{l}\text { Ground } \\
\text { Transportation }\end{array}$} & \multirow[t]{2}{*}{$\begin{array}{l}\text { Industry } \\
\text { Process }\end{array}$} & \multirow[t]{2}{*}{ Waste } & \multicolumn{3}{|c|}{ Summary } \\
\hline & & & & & & $\begin{array}{l}\text { Industry } \\
\text { related }^{\mathrm{c}}\end{array}$ & $\begin{array}{l}\text { Non } \\
\text { Industry }\end{array}$ & Total \\
\hline Bangkok & 2.77 & 2.49 & 2.27 & unknown & 1.23 & 2.63 & 6.13 & 8.76 \\
\hline Barcelona & 0.67 & 0.85 & 0.77 & unknown & 0.24 & 0.76 & 1.77 & 2.53 \\
\hline Cape Town & 3.38 & 1.15 & 1.44 & unknown & 1.78 & 2.33 & 5.43 & 7.75 \\
\hline Denver & 9.10 & 4.12 & 6.31 & unknown & 0.59 & 6.04 & 14.08 & 20.12 \\
\hline Geneva & 0.35 & 3.45 & 1.85 & unknown & 0.38 & 1.81 & 4.22 & 6.03 \\
\hline London & 2.50 & 2.58 & 1.22 & unknown & 0.21 & 1.95 & 4.56 & 6.51 \\
\hline Los Angeles & 2.46 & 1.37 & 4.92 & 0.22 & 0.49 & 2.84 & 6.62 & 9.46 \\
\hline New York & 3.01 & 3.13 & 1.53 & unknown & 0.35 & 2.41 & 5.61 & 8.02 \\
\hline Prague & 3.31 & 3.20 & 1.44 & 0.43 & 0.11 & 2.55 & 5.94 & 8.49 \\
\hline Toronto & 2.47 & 3.30 & 4.05 & 0.57 & 0.33 & 3.22 & 7.50 & 10.72 \\
\hline Beijing & 3.40 & 3.01 & 1.46 & 0.61 & 0.14 & 5.12 & 3.50 & 8.62 \\
\hline Tianjin & 3.53 & 7.07 & 0.90 & 0.42 & 0.16 & 10.04 & 2.03 & 12.07 \\
\hline Shanghai & 4.82 & 3.77 & 0.95 & 0.83 & 0.19 & 7.44 & 3.13 & 10.57 \\
\hline Hangzhou & 3.42 & 3.71 & 1.03 & 1.05 & 0.66 & 7.61 & 2.26 & 9.87 \\
\hline Nanjing & 3.34 & 1.99 & 0.64 & 1.62 & 0.12 & 5.31 & 2.40 & 7.71 \\
\hline Wuxi & 7.00 & 6.23 & 1.13 & 1.72 & 0.38 & 12.78 & 3.67 & 16.45 \\
\hline Guangzhou & 3.27 & 1.87 & 1.57 & 0.98 & 0.17 & 4.47 & 3.39 & 7.86 \\
\hline Zhengzhou & 3.10 & 3.39 & 0.81 & 1.44 & 0.50 & 6.32 & 2.92 & 9.24 \\
\hline Wuhan & 1.16 & 11.16 & 0.77 & 0.60 & 0.16 & 12.59 & 1.25 & 13.84 \\
\hline Chongqing & 0.76 & 1.22 & 0.35 & 0.43 & 0.13 & 2.03 & 0.85 & 2.88 \\
\hline Lanzhou & 3.51 & 15.13 & $0.3^{b}$ & 2.26 & 0.13 & 20.71 & 0.32 & 21.04 \\
\hline Shenyang & 1.93 & 3.44 & 1.01 & 0.12 & 0.17 & 4.62 & 2.06 & 6.68 \\
\hline
\end{tabular}

a The carbon emissions data of bold italic marked cities are from this study and the data of other ten cities in the world are from Kennedy's study (2009).

${ }^{b}$ Because no information about vehicle population was found for Lanzhou city, the analogy analysis between Zhengzhou and Lanzhou was applied to calculate the carbon emissions.

${ }^{\mathrm{c}}$ For the ten cities in the world used for comparison in this study, information on industry-related emissions is lacking. Thus it is assumed that industry contributes $30 \%$ of total per capita carbon emissions, which is similar to the proportion of average US level (the Fifth US Climate Action Report,

http://www.state.gov/e/oes/rls/rpts/car5/index.htm).

average level, which may be different from the actual situation in specific cities.

3. Uncertainty associated with the integrity of carbon accounting. Restricted by data availability, we only calculated carbon emissions from key industrial processes, including the mineral products industry (cement, glass, etc.), chemicals, and metal production. The consequence would be to underestimate the carbon emissions from industrial processes. Quantitative analyses of these types of uncertainties will be conducted in our future studies, when more basic information on carbon emissions in Chinese cities is available.

\section{Conclusions and future work}

In this study, carbon emissions of 12 Chinese cities from 2004 to 2008 were calculated using a bottom-up methodology. In sum:

1. Total carbon emissions, per capita and per unit of GDP emissions varied greatly due to city-specific factors, such as energy structures, economic development and structures, populations, and first of all the structures of industry sectors in each city. Emissions in most Chinese cities rose along with economic growth from 2004 to 2008. For most cities, per unit of GDP emissions declined while per capita emissions grew. Total carbon emission, per capita and per unit of GDP emissions varied between the highest and lowest emitting cities by factors of nearly 7, 10 and 4, respectively.

2. Contributions of individual sectors to total per capita carbon emissions were as follows: industrial energy consumption $(65.1 \%)$, industrial processes $(10.1 \%)$, transportation $(10.4 \%)$, household energy consumption $(7.7 \%)$, commercial energy consumption $(4.2 \%)$, and waste processing $(2.5 \%)$. However, these shares are also characterized by large variability due to cityspecific factors.

3. Levels of per capita carbon emissions in China's cities were higher than we anticipated due to the higher contribution of the industrial sector to the total carbon 
emissions. If we exclude the impact of industrial carbon emissions, the average per capita non-industrial emission of Chinese cities is only $37 \%$ of the ten world cities. This illustrates that the carbon emissions of Chinese cities are mainly attributable to industrial activities and carbon emissions from citizen's everyday life are far below the average levels of global countries.

This study preliminarily analyzed the carbon emission characteristics of 12 Chinese cities. Other factors, such as a city's climate (e.g. geographical location influences heating/cooling energy consumption in cities), industrial structure, energy structure and energy prices, may also play a substantial role in accounting for total GHG emissions (Kennedy et al., 2009; Zhao et al., 2010a). To develop a better understanding of the factors determining the emission trends in China a quantitative decomposition analysis should be performed (Dhakal, 2009; Minx et al., 2011). We plan to perform such an analysis in future studies.

As industry is the major contributor to the total carbon emissions of the cities in China, more work is needed to analyze the opportunities to improve industrial energy and material consumption efficiencies in this sector. With continuing rapid urbanization, the development of benchmarks of GHG emissions caused by city activities will definitely have a large impact on climate action plans for China and the world. Also, it should be noted that we have not attempted to include carbon emissions from cross-boundary activities, such as international air travel or embodied energy consumption associated with products produced or consumed in cities (e.g. food, water and fuel). These are also major contributors to emissions in developed countries (Hillman and Ramaswami, 2010; Kennedy et al., 2009). As China is a major producer of products and commodities consumed abroad, adopting a consumption perspective would significantly affect comparisons between China's cities and the ten world cities. This topic will merit attention in future research.

\section{Supplementary material related to this article is available online at: http://www.atmos-chem-phys.net/12/ 6197/2012/acp-12-6197-2012-supplement.pdf.}

\begin{abstract}
Acknowledgements. This work was supported by China National Program on Key Basic Research Project (973 Program, Project No. 2010CB950704), China National Nature Science Foundation (Project No. 51008155) and Foundation Research Project of Jiangsu Province (The Natural Science Fund No. BK2011017). We also thank the two anonymous referees for their constructive comments to improve our paper. The contents of this paper are solely the responsibility of the authors and do not necessarily represent official views of the sponsors.
\end{abstract}

Edited by: M. Gauss

\section{References}

Bi, J., Zhang, R., Wang, H., Liu, M., and Wu, Y.: The Benchmarks of Carbon Emissions and Policy Implications for China's Cities: Case of Nanjing, Energy Policy, 39, 4785-4794, 2011.

Chen, Y., Yang, Z., Fang, S., Hu, Z., Matin, M., and Sujit, B.: A patent based evaluation of technological innovation capability in eight economic regions in PR China, World Patent Information, 31, 104-110, 2009.

Dhakal, S.: Urban energy use and carbon emissions from China and policy implications, Energy Policy, 37, 4208-4219, 2009.

Gertz, M.: New research aims to create accurate account of a city's carbon burden, Environ. Sci. Technol, 43, 8006-8007, 2009.

Gurney, K. R., Mendoza, D. L., Zhou, Y., Fischer, M. L., Miller, C. C., Geethakumar, S., and de la Rue du Can, S.: High resolution fossil fuel combustion $\mathrm{CO}_{2}$ emission fluxes for the United States, Environ. Sci. Technol., 43, 5535-5541, 2009.

He, K., Huo, H., Zhang, Q., He, D., An, F., Wang, M., and Walsh, M.: Oil consumption and $\mathrm{CO}_{2}$ emissions in China's road transport: current status, future trends, and policy implications, Energy Policy, 33, 1499-1507, 2005.

Hillman, T. and Ramaswami, A.: Greenhouse gas emission footprints and energy use benchmarks for eight U.S. cities, Environ. Sci. Technol, 44, 1902-1910, 2010.

Houghton, R. A. and Hackler, J. L.: Emissions of carbon from forestry and land-use change in tropical Asia, Global Change Biol., 5, 481-492, 1999.

Huo, H., Zhang, Q., Wang, M., Streets, D., and He, K.: Environmental implication of electric vehicles in China, Environ. Sci. Technol., 44, 4856-4861, 2010.

ICLEI: Cities for Climate Protection, Toronto, Canada: International Council of Local Environmental Initiatives, available at: http://www.iclei.org/index.php?id=800 (last access: December 2010), 2008.

IEA (International Energy Agency): $\mathrm{CO}_{2}$ Emissions from Fuel Combustion 1971-2005, Paris: Organization for Economic Cooperation and Development, 2007.

IPCC (Intergovernmental Panel on Climate Change): 2006 IPCC Guidelines for National Greenhouse Gas Inventories, Prepared by the National Greenhouse Gas Inventories Programme, edited by: Eggleston, H. S., Buendia, L., Miwa, K., Ngara, T., and Tanabe, K., IGES: Japan, 2006.

Kennedy, C., Steinberger, J., Casson, B., Hansen, Y., Hillman, T., Havránek, M., Pataki, D., Phdungsilp, A., Ramaswami, A., and Mendez, G.: Greenhouse gas emissions from global cities, Environ. Sci. Technol, 43, 7297-7302, 2009.

Kennedy, C., Steinberger, J., Casson, B., Hansen, Y., Hillman, T., Havránek, M., Pataki, D., Phdungsilp, A., Ramaswami, A., and Mendez, G.: Methodology for inventorying greenhouse gas emissions from global cities, Energy Policy, 38, 4828-4837, 2010.

Koehn, P. H.: Underneath Kyoto: emerging subnational government initiatives and incipient issue-bundling opportunities in China and the United States, Global Environ. Politics, 8, 53-57, 2008.

Larsen, H. and Hertwich, E.: The case for consumption-based accounting of greenhouse gas emissions to promote local climate action, Environ. Sci. Policy, 12, 791-798, 2009.

Li, L., Chen, C., Xie, S., Huang, C., Cheng, Z., Wang, H., Wang, Y., Huang, H., Lu, J., and Dhakal, S.: Energy demand and carbon emissions under different development scenarios for Shanghai, 
China, Energy Policy, 38, 4797-4807, 2010.

Lin, J., Cao, B., Cui, S., Wang, W., and Bai, X.: Evaluating the effectiveness of urban energy conservation and GHG mitigation measures: The case of Xiamen city, China, Energy Policy, 38, 5123-5132, 2010.

Matthews, H. S., Hendrickson, C. T., and Weber, C. L.: The importance of carbon footprint estimation boundaries, Environ. Sci. Technol., 42, 5839-5842, 2008.

Minx, J. C., Baiocchi, G., Peters, G. P., Weber, C. L., Guan, D., and Hubacek, K.: A “Carbonizing Dragon”: China's Fast Growing $\mathrm{CO}_{2}$ Emissions Revisited, Environ. Sci. Technol., 45, 9144 9153, 2011.

Ramaswami, A., Hillman, T., Janson, B., Reiner, M., and Thomas, G.: A demand-centered, hybrid life cycle methodology for cityscale greenhouse gas emissions, Environ. Sci. Technol., 42, 6455-6461, 2008.

Satterthwaite, D.: Cities' contribution to global warming: notes on the allocation of greenhouse gas emissions, Environment and Urbanization, 20, 539-549, 2008.

Schulz, N.: Delving into the carbon footprints of Singaporecomparing direct and indirect greenhouse gas emissions of a small and open economic system, Energy Policy, 38, 4848-4855, 2010.

SSBC (State Statistical Bureau of China): Electricity Yearbook of China 2009, China Statistics Press: Beijing, China, 2009.

UN: World urbanization prospects: the 2007 revision, United Nations Population, Population Division of the Department of Economic and Social Affairs, available at: http://esa.un.org (last access: November 2010), 2007.
Wang H., Fu L., Zhou, Y., Du, X., and Ge, W.: Trends in vehicular emissions in China's mega cities from 1995 to 2005, Environ. Pollut., 158, 394-400, 2010a.

Wang, S., Zhao, M., Xing, J., Wu, Y., Zhou, Y., Lei, Y., He, K., Fu, L., and Hao, J.: Quantifying the air pollutants emission reduction during the 2008 Olympic Games in Beijing, Environ. Sci. Technol., 44, 2490-2496, 2010b.

Wang, H., Fu, L., and $\mathrm{Bi}, \mathrm{J} .: \mathrm{CO}_{2}$ and pollutant emissions from passenger car in China, Energy Policy, 39, 3005-3011, 2011.

Yantosca, M., Xiao, Y., Evans, J., Streets, G., Vay, L., and Sachse, W.: Improved quantification of Chinese carbon fluxes using CO2//CO correlations in Asian outflow, J. Geophys. Res., 109, D18S18, doi:10.1029/2003JD004362, 2004.

Zhao, M., Tan, L., Zhang, W., Ji, M., Liu, Y., and Yu, L.: Decomposing the influencing factors of industrial carbon emissions in Shanghai using the LMDI method, Energy, 35, 2505-2510, 2010a.

Zhou, Y., Wu, Y., Yang, L., Fu, L., He, K., Wang, S., Hao, J., Chen, J., and Li, C.: The impact of transportation control measures on emission reductions during the 2008 Olympic Games in Beijing, China, Atmos. Environ., 44, 285-293, 2010b. 